\section{Dr. Mäkinen and Dr. Hannonen reply}

\section{To the Editor:}

We are delighted that Dr. Pincus has responded to the recent article by Coury, et $a l^{1}$ and our accompanying editorial ${ }^{2}$ regarding the problematic assessment of disease activity in patients with rheumatoid arthritis (RA) and concomitant fibromyalgia (FM). Both disorders are rather common, but to a physician familiar with rheumatic disorders, differentiation of the 2 syndromes is not a problem, nor is assessment of patients having both disorders concomitantly.

The hallmark of RA is systemic inflammation, whereas FM is characterized by disordered pain perception. Consequently, the "target organs" of RA are synovial joints, while most emerging findings in FM indicate lowered pain thresholds of patients. Thus, in active RA one finds swollen and tender joints, while in FM the patient is "tender all over." Quite often both disorders may show activity simultaneously.

Nevertheless, most rheumatologists are able to discern these clinical entities provided a thorough clinical examination is conducted. No laboratory testing or imaging investigations are needed to separate active RA from active FM. In our experience, problems arise if the physician does not devote enough time for careful history-taking and thorough clinical examination, but instead sends the patient for (extensive) laboratory testing and to the imaging unit.

The increased popularity of the use of various composite indices (especially the DAS28 ${ }^{3}$ ) to assess disease activity has created a new "problem." Although these composite indices work well in groups of patients, they may not do so on an individual level. Thus, the indices work excellently in controlled clinical trials and other scientific projects. In a clinical setting, however, a physician should not make his/her decisions (especially when targeting therapies) based on these indices only, but should always complete a proper clinical examination.

As pointed out by Pincus, a patient with FM presents disproportionately high scores for pain and fatigue and an unexpectedly wide symptom spectrum with regard to their function. As an experienced clinician he also discusses whether the approach reported by a patient should be considered as "true" instead of the "objective" data valued by most physicians.
Self-report questionnaires including the Health Assessment Questionnaire, Multidimensional HAQ, and the Fibromyalgia Impact Questionnaire, etc. have been a big step forward in the specialty of rheumatology; unfortunately, they are not fully utilized. Nevertheless, the patient's history and tools such as self-report assessment questionnaires and DAS28 must be supported by the special knowledge and skills of the physician.

The enduring principle in all medicine is that decision-making is a shared task between a physician and a patient. Shared decision-making means that the physician should carefully listen to what the patient says. Since the patient usually is right, the physician should not doubt the patient's truthfulness, but his/her role is to provide an interpretation. After listening and hearing the patient, the physician expresses his/her opinion only after a careful clinical examination. In an optimal situation, patient and physician part with mutual agreement about the diagnosis and treatments, which may be corrected during subsequent visits.

HEIDI MÄKINEN, MD, PhD, Department of Rheumatology, Tampere University Hospital, PL 2000 Tampere, 33521 Finland; PEKKA HANNONEN, MD, PhD, Department of Rheumatology, Jyväskylä Central Hospital, Jyväskylä, Finland. Address reprint requests to Dr. H. Mäkinen; E-mail: heidi.makinen@ksshp.fi

\section{REFERENCES}

1. Coury F, Rossat A, Tebib A, et al. Rheumatoid arthritis and fibromyalgia: a frequent unrelated association complicating disease management. J Rheumatol 2009;36:58-62.

2. Makinen H, Hannonen P. How to assess patients with rheumatoid arthritis and concomitant fibromyalgia? [editorial]. J Rheumatol 2009;36:9-11.

3. Prevoo MLL, van 't Hof MA, Kuper HH, van Leeuwen MA, van de Putte LBA, van Riel PLCM. Modified disease activity scores that include twenty-eight-joint counts: Development and validation in a prospective longitudinal study of patients with rheumatoid arthritis. Arthritis Rheum 1995;38:44-8.

J Rheumatol 2009;36:9; doi:10.3899/jrheum.090443 